Rev. Saride públ., S. Paulo

$3(1): 59-65$, jun. 1969.

\title{
FOCOS ATIVOS DE ESQUISTOSSOMOSE MANSONI NO VALE DO RIBEIRA, ESTADO DE SÃO PAULO, BRASIL (1)
}

\author{
Alberto da Silva RAMOS (2) \\ José de Toledo PIZA (3) \\ Geraldo Henriques PINTO (4) \\ Taminato TION (4) \\ Gilda Corrêa FLEURY (5) \\ Lúcia Vieira C. MORAIS (5) \\ Lúcia Lacerda CAMPOS (5)
}

Ramos, A. da S. et al. - Focos ativos de esquistossomose mansoni no Vale do Ribeira, Estado de São Paulo, Brasil. Rev. Saúde públ., S. Paulo, 3(1): 59-65, jun. 1969.

RESUMo - São apresentados os resultados das investigaçōes sôbre os focos de esquistossomose nas localidades de Pedro de Toledo e Itariri, com referência especial aos índices de infecção natural obtidos para a espécie Biomphalaria tenagophila. Este molusco, transmissor de esquistossomose no Vale do Ribeira já foi assinalado nos seguintes municípios daquela regiāo: Eldorado, Iguape, Itariri, Jacupiranga, Juquiá, Miracatu, Pariqueraçu, Pedro de Toledo, Registro e Sete Barras. Os índices cercáricos de $68,1 \%, 75,0 \%$ e $81,3 \%$ obtidos em alguns lotes de $B$. tenagophila, os mais altos já verificados para esta espécie, vem mais uma vez comprovar sua grande suscetibilidade à infecção pelo Schistosoma mansoni.

\section{N T R O D U C A O}

O Vale do Ribeira, região situada no sudeste do Estado de São Paulo, apresenta uma bacia hidrográfica formada pelo Rio Ribeira do Iguape e por extensa rêde hídrica que confere àquela zona características especiais; entre os fatôres climáticos, destaca-se a pluviosidade média anual de $2.500 \mathrm{~mm}$, que nas áreas de culturas, especialmente bananas, e também nas cidades, propicia condições favoráveis à proliferação dos moluscos.

As péssimas condiçôes sanitárias das localidades e a presença de portadores de esquistossomose que se fixaram naquela

Recebido para publicação em 28-2-1969.

(1) Trabalho apresentado em sessão de 11-9-1968 do Departamento de Higiene e Medicina Tropical da Associação Paulista de Medicina - São Paulo, Brasil.

(2) Da Escola Paulista de Medicina - São Paulo, Brasil (Comissionado junto à Secretaria de Saúde Pública do Estado de São Paulo - São Paulo).

(3) Da Campanha cie Combate a Esquistossomose - São Paulo, Brasil.

(4) Da Divisão do Serviço do Interior - Secretaria de Saúde Pública do Estado de São Paulo - São Paulo, Brasil.

(5) Do Instituto Adolfo Lutz - São Paulo, Brasil. 
RAMOS, A. da S. et al. - Focos ativos de esquistossomose mansoni no Vale do Ribeira, Estado de São Paulo, Brasil. Rev. Saúde públ., S. Paulo, 3(1):59-65, jun. 1969.

zona, determinaram a mesma ocorrência já verificada em outras regióes do Estado, isto é, a instalaçáo de focos autóctones da doença. A expansão da parasitose no Estado de São Paulo é fato conhecido; uma vez estabelecido o primeiro foco em uma localidade, alastra-se para a vizinhança, dilatando sempre a sua área de incidência.

Data de 1953 a primeira referência à parasitose do Vale do Ribeira, com a descoberta feita por NogueIRA ${ }^{2}$, de um foco autóctone no Distrito de Ana Dias, município de Itariri. Posteriormente foi a helmintose localizada na sede dêste Município, no distrito de Raposo Tavares, e nos Bairros de Fortaleza e Anta Gorda. Ainda nas localidades de Pedro de Toledo, Miracatu e Juquiá, foram registrados casos de doença que estão sendo investigados.

Com relação à espécie vetora de esquistossomose naquela zona, Biomphalaria tenagophila, foi assinalada nos seguintes municípios: Eldorado, Iguape, Itariri, Jacupiranga, Juquiá, Miracatu, Pariqueraçu, Pedro de Toledo, Registro e Sete Barras.

\section{A TERAL E METODOS}

As pesquisas foram realizadas nas cidades de Pedro de Toledo e Itariri, sedes dos respectivos municípios.

Os focos ativos, à medida que iam sendo descobertos, eram numerados, a fim de facilitar a sua identificação e permitir as repetidas coletas de material em datas diferentes e as observações de suas características. A captura dos moluscos e seu acondicionamento para o transporte ao laboratório foram executados pelos proces. sos rotineiros.

As observaçōes sôbre os biótipos dos planorbídeos consistiam na verificação do tipo de criadouro, aspecto, temperatura e pH da água, bem como a existência de vegetação aquática e marginal.

Foram inoculados pelo método de Brenner, 2 lotes de camundongos albinos (Mus mus) com cercárias obtidas dos moluscos coletados nos focos e expostos à ação das cercárias em natureza mais 2 outros lotes. $O$ material foi examinado no Instituto Adolfo Lutz e na Cadeira de Parasitologia da Escola Paulista de Medicina.

As investigações aqui descritas, baseadas em material coletado no período de 23 de julho a 28 de agôsto do ano de 1968, constituem parte do levantamento epidemiológico em execução naquelas lo. calidades.

\section{R E S U L T A O S}

\section{Pedro de Toledo}

A cidade de Pedro de Toledo distante $160 \mathrm{~km}$ da Capital, está localizada a $24^{\circ}, 16^{\prime}$ de latitude sul e $47^{\circ}, 14^{\prime}$ de longitude W.Gr., altitude de $43,50 \mathrm{~m}$. O clima é quente, com média mensal de temperatura entre 18 e $22^{\circ} \mathrm{C}$, e chuvas de 1.500 a $1.900 \mathrm{~mm}$.

A área do município é de $631 \mathrm{~m}^{2}$, população de 4.450 habitantes, sendo 1.950 na zona urbana e 2.500 na rural. Dispõe a localidade de abastecimento de água para 329 prédios, uma rêde de esgotos muito precária que serve 30 casas e ainda 284 fossas; na periferia as casas não dispóem de fossas.

A cidade, que está localizada numa es. pécie de bacia formada pelas ondulações da Serra Itatins é montanhosa, estendendo-se por três vertentes: uma na zona Leste, cujas águas vão ter ao Rio do Peixe; outra no centro urbano, que ocupa quase todo o vale percorrido pelo Córrego das Enchentes, o qual vai desaguar no Rio Itariri; a terceira vertente, a Oeste da cidade, tem como principal curso d'água o córrego da Vila Sorocabana, que vai desaguar também no Rio Itariri.

Esquistossomose: seis casos autóctones tinham sido registrados pela unidade sanitária local desde 1959 (Piza \& Ramos ${ }^{4}$, 1960). Êste aspecto será tratado pormenorizadamente, quando estiver concluído o levantamento coprológico que ali se processa. 
RAMOS, A. da $S$. et al. - Focos ativos de esquistossomose mansoni no Vale do Ribeira, Estado de São Paulo, Brasil. Rev. Saride públ., S. Paulo, 3(1):59-65, jun. 1969.

Planorbideos: pesquisas anteriores revelaram a existência da espécie $B$. tenagophila na localidade, porém, dos 126 exemplares examinados, de coletas levadas a efeito em 1960 e 1961, nenhum estava parasitado. Sòmente agora, foi pela primeira vez encontrado naquela cidade, êste molusco naturalmente. infectado pelo Schistosoma mansoni, conforme resultados abaixo descritos.

\section{Localização dos focos}

Foram localizados os seguintes focos ativos de esquistossomose na zona urbana e que são os seguintes:

\section{Foco $n .^{\circ} 1$}

Situado no quintal de uma casa na Praça dos f́ndios onde existe uma horta e alguns pés de bananas (Chácara do Japonês). Éste quintal é cortado pelo Córrego das Enchentes, que constitui o criadouro de planorbídeos e que nesta época do ano mede de $60 \mathrm{~cm}$ a um metro de

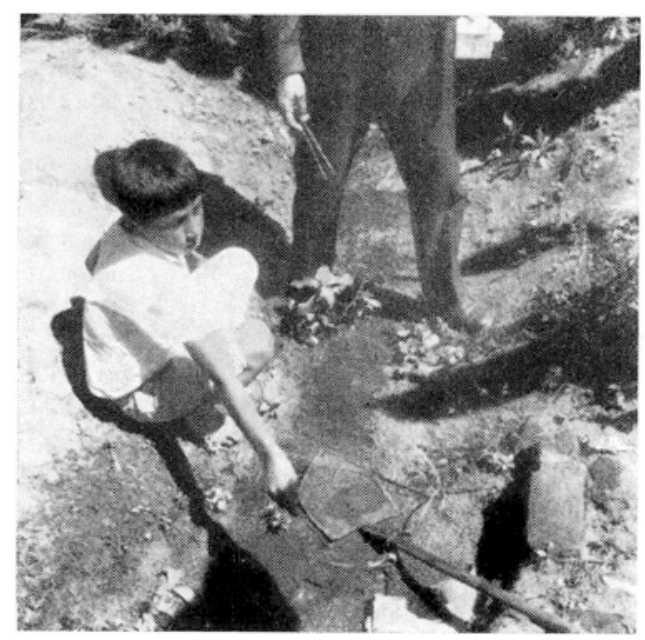

Fig. 1 - Pequeno curso d'água muito raso, onde foram capturados lotes de $B$. tenagophila com indices de infecção natural de $53,1 \%$ a $81,3 \%$ para o S. mansoni (Foco 2 ). largura, margens irregulares, muito raso; a lâmina d'água apresentava-se com 15 a $30 \mathrm{~cm}$ de largura e 10 a $15 \mathrm{~cm}$ de profundidade, variável em certos pontos; a água é de vazão lenta, fundo lodoso com touceiras de "chapéu de sapo" (Eichornia diversifolia), muito poluída por excretos humanos, com detritos, insetos e algas.

A temperatura da água, observada em várias ocasiōes variava de 19 a $21^{\circ} \mathrm{C}$; o pH apresentou valores oscilando entre 5,5 e 6,0 .

Os índices de infecção natural verificado para Biomphalaria tenagophila são apresentados abaixo juntamente com as datas da captura dos moluscos:

$\begin{array}{rccc}\text { Data } & \begin{array}{c}\text { Exemplares } \\ \text { examinados }\end{array} & \text { Positivos } & \begin{array}{c}\text { fndice de } \\ \text { infecç̃o }\end{array} \\ 23-7-68 & 22 & 15 & 68,1 \% \\ 31-7-68 & 63 & 22 & 34,9 \% \\ 5-8-68 & 53 & 21 & 39,6 \% \\ 5-8-68 & 72 & 26 & 36,1 \% \\ 20-8-68 & 140 & 59 & 42,1 \% \\ 21-8-68 & 96 & 31 & 32,2 \% \\ 28-8-68 & 159 & 16 & 10,0 \%\end{array}$

\section{Foco $n .^{\circ} 2$}

Pequeno curso d'água que atravessa o quintal da casa $n .^{\circ} 9$ da Rua Guarapana, originário de pequena nascente aí existente, mede $15 \mathrm{~m}$, desde a nascente, até o Córrego das Enchentes, onde vai desaguar. Muito raso com lâmina d'água de $10 \mathrm{~cm}$ de largura por 2 e $5 \mathrm{~cm}$ de profundidade, é pouco mais que um filete d'água. Água limpa, parcialmente sombreada, de fundo lodoso e que não recebe despejos de esgotos. A temperatura da água variava de 19 a $20^{\circ} \mathrm{C}$, e o $\mathrm{pH}$ foi de 5,5 .

\section{Espécie: Biomphalaria tenagophila.}

Os índices de infecção natural são os seguintes: 
RAMOS, A. da S. et al. - Focos ativos de esquistossomose mansoní no Vale do Ribeira, Estado de São Paulo, Brasil. Rev. Saúde públ., S. Paulo, 3(1):59-65, jun. 1969.

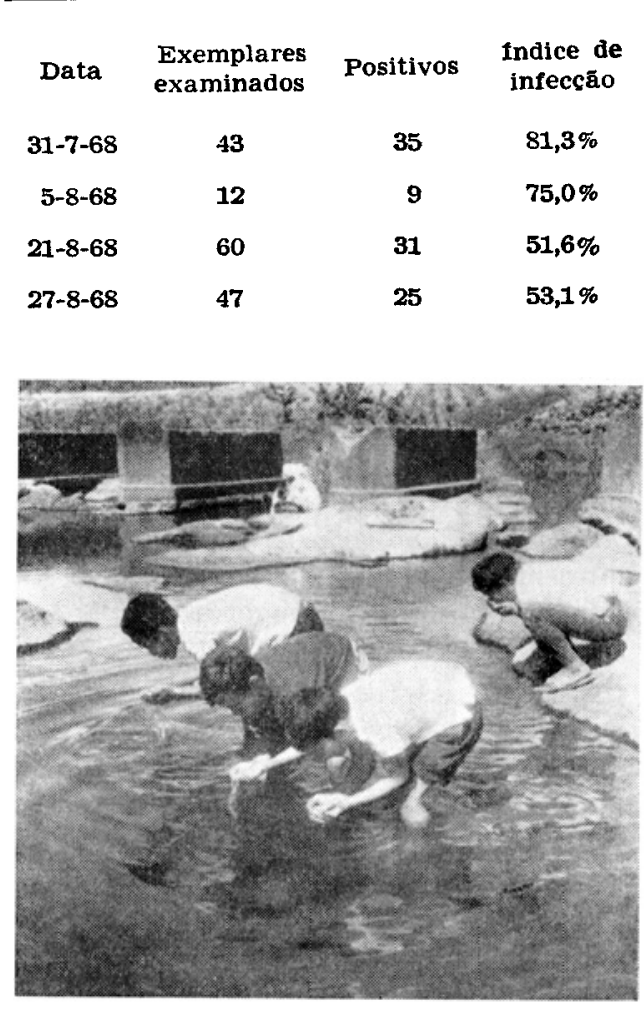

Fig. 2 - Local à margem esquerda do Rio do Peixe, na zona urbana de Pedro de Toledo, freqüentado principalmente por escolares (Foco 3$)$.

\section{Foco $n .^{\circ} 3$}

Avenida São José. Este foco foi locali. zado no remanso da margem esquerda do Rio do Peixe, no ponto em que êste entra na cidade fazendo uma curva, margeando aquela avenida. Neste local, o rio é pedregoso, raso, sendo um atrativo para a população, que na estação quente aí vai, para recreação, banho ou lavagem de roupa. Os moluscos são encontrados na vegetação da margem e na água das escavaçōes das rochas ai dispersas, onde a temperatura era $20^{\circ} \mathrm{C}$ e o pH 6,0 . A água do rio é limpa, de vazão lenta junto à margem com a temperatura variando entre 19 e $21^{\circ} \mathrm{C}$, nas observaçōes obtidas entre 10 e 16,30 horas. O valor do $\mathrm{pH}$ foi de 5,5 .
Espécie: Biomphalaria tenagophila.

$\begin{array}{cccc}\text { Data } & \begin{array}{c}\text { Exemplares } \\ \text { examinados }\end{array} & \text { Positivos } & \begin{array}{c}\text { indice de } \\ \text { infecção }\end{array} \\ \text { 21-8-68 } & 198 & 34 & 17,1 \%\end{array}$

Foram coletados exemplares de Lymnaeidae e Physidae.

\section{Foco $n .^{\circ} 4$}

Escavação de pedra, à margem esquerda do Rio do Peixe, na entrada da cidade. 0 foco retangular medindo $1,5 \mathrm{~m}$ de com. primento por $80 \mathrm{~cm}$ de largura e $50 \mathrm{~cm}$ de profundidade; água turva, esverdeada, de fundo lodoso, com algas, insetos e girinos, sendo de capim a vegetação marginal. $\mathrm{O} \mathrm{pH}$ da água era 6,0 .

\section{Espécie: Biomphalaria tenagophila.}

$\begin{array}{cccc}\text { Data } & \begin{array}{c}\text { Exemplares } \\ \text { examinados }\end{array} & \text { Positivos } & \begin{array}{c}\text { fndice de } \\ \text { infeccão }\end{array} \\ \text { 27-8-68 } & 52 & 18 & 34,6 \%\end{array}$

\section{Foco $n .^{\circ} 5$}

Escavação de pedra, à margem esquerda do Rio da Peixe, na entrada da cidade. $O$ criadouro mede $50 \mathrm{~cm}$ por $40 \mathrm{~cm}$, e 30 cm de profundidade; água turva, com algas, insetos e girinos, $\mathrm{pH}$ igual a 6,0 .

\section{Espécie: Biomphalaria tenagophila.}

Data $\begin{gathered}\text { Exemplares } \\ \text { examinados }\end{gathered}$ Positivos $\begin{gathered}\text { fndice de } \\ \text { infecção }\end{gathered}$

$\begin{array}{llll}27-8-68 & 6 & 2 & 33,3 \%\end{array}$

\section{Infecção experimental de camundongos}

Lote $n .0^{\circ} 1$ : foram inoculados 5 camundongos albinos com cercárias obtidas de 10 exemplares de $B$. tenagophila capturados no Foco 2.

Lote $n^{\circ}$ 2: 8 camundongos albinos inoculados com cercárias eliminadas por 20 exemplares de $B$. tenagophila colhidos no Foco n. 3. 
RAMOS, A. da S. et al. - Focos ativos de esquistossomose mansoni no Vale do Ribeira, Estado de São Paulo, Brasil. Rev. Saúde públ., S. Paulo, 3(1):59-65, jun. 1969.

Após necropsia aos 64 dias da inoculação foram obtidos os seguintes resultados: no Lote 1, todos os exemplares apresen. taram-se com a infecção sendo que 3 dêles eliminaram ovos a partir do $500^{\circ}$ dia; no Lote 2 , foi constatada a infecção em 5 exemplares, pois os 3 restantes morreram antes de serem examinados.

\section{Exposição de camundongos nos focos}

Lote $n .^{\circ} 1$ : constituído por 8 camundongos albinos, êste lote foi exposto durante 30 minutos no Foco n. ${ }^{\circ} 1$, tendo início às 12,20 horas do dia 5-8-68. A temperatura do ar era de $26^{\circ} \mathrm{C}$ e da água $20^{\circ} \mathrm{C}$. Após necropsia aos 150 dias da exposição, foram obtidos os seguintes resultados: dos 7 camundongos examinados, 4 se apresentaram com a infecção, sendo 3,5 a mé. dia de esquistossomos recuperados. Um animal morreu sem ser examinado.

Lote $n .^{\circ}$ 2: oito exemplares de camundongos expostos no Foco $n .^{\circ} 2$, durante 30 minutos, simultâneamente com o Lote n..$^{\circ}$, e nas mesmas condições ambientais. Dois animais foram examinados após necropsia aos 35 dias e o restante depois de 150 dias, com os seguintes resultados quanto à recuperação dos vermes: $n .^{\circ} \mathbf{l}$, dois machos, n. 2 dois casais, n. $^{\circ} 3$ dois machos e dois, casais, $n .^{\circ} 4$ um macho, $n .^{\circ}$ 5 vinte e cinco fêmeas, $n .^{\circ} 6$ negativo, $n .^{\circ}$ 7 um macho e n. 8 um casal.

\section{ITARIRI}

A cidade de Itariri, distante $150 \mathrm{~km}$ da Capital, fica localizada nos paralelos $24^{\circ}, 17^{\prime}$ de latitude sul e $47^{\circ}, 11^{\prime}$ de longitude W.Gr. Sua altitude é de $52 \mathrm{~m}$, clima temperado, com temperatura média das máximas de $23^{\circ} \mathrm{C}$ e média das mínimas de $17^{\circ} \mathrm{C}$. Pluviosidade de $1.351,2$ $\mathrm{mm}$. A área do municipio é de $298 \mathrm{~km}^{2}$, com população de 12.000 habitantes, sendo 3.000 na sede e 9.000 na zona rural. Conta com abastecimento de água para
190 prédios e 3 chafarizes público. Rêde de esgotos e 150 fossas. Na periferia da cidade existem casas sem fossas.

Esquistossomose: o primeiro foco autóctone foi descoberto por NogUeIRA ${ }^{2}$ (1953) no distrito de Ana Dias, sendo posteriormente registrados outros focos em diferentes pontos do município.

Planorbideos: a espécie transmissora encontrada na sede e na área restante do município, foi B. tenagophila. Os resultados de pesquisas realizadas anteriormente, de 1953 até o início destas observações, pela Comissão de Esquistossomose, apresentam 8.425 exemplares colhidos e examinados, dos quais foram obtidos índices de infecção natural desde $3,7 \%$ até $51,3 \%$ para o distrito de Ana Dias.

As pesquisas atuais dizem respeito à cidade de Itariri, onde até o presente não havia sido encontrada a espécie com infecção pelo trematódeo. São os seguintes resultados:

\section{Foco $n .^{\circ} 1$}

Vala de drenagem na zona urbana que recebe despejos de esgotos. Rua Projetada, s/número. Agua turva, com detritos, peixes, girinos, insetos e algas.

\section{Espécie: Biomphalaria tenagophila.}

$\begin{array}{cccc}\text { Data } & \begin{array}{r}\text { Exemplares } \\ \text { examinados }\end{array} & \begin{array}{c}\text { Posit. p/ } \\ \text { S. mansoni }\end{array} & \begin{array}{c}\text { Indice de } \\ \text { infecção }\end{array} \\ \text { 23-7-68 } & 93 & 7 & 7,5 \%\end{array}$

\section{Foco $n 0^{\circ} 2$}

Vala que recebe despejos de esgotos e atravessa um pequeno bananal. Agua tur$\mathrm{va}$, com detritos, algas, peixes, girinos e insetos. Chácara do Sr. Manoel Joaquim.

\section{Espécie: Biomphalaria tenagophila.}

$\begin{array}{cccc}\text { Data } & \begin{array}{c}\text { Exemplares } \\ \text { examinados }\end{array} & \begin{array}{c}\text { Posit. p/ } \\ \text { S. mansoni }\end{array} & \begin{array}{c}\text { Indice de } \\ \text { infecção }\end{array} \\ \text { 23-7-68 } & 142 & 18 & 12,6 \%\end{array}$


RAMOS, A. da $S$. et al. - Focos ativos de esquistossomose mansoni no Vale do Ribeira, Estado de São Paulo, Brasil. Rev. Saúde públ., S. Paulo, 3(1):59-65, jun. 1969.

\section{I S C U S A O}

A espécie Biomphalaria tenagophila, com larga distribuição no Estado de São Paulo, sòmente foi reconhecida como importante hospedeira intermediária do Schistosoma mansoni, após a comprovação de altos índices de infecção natural por MARTins ${ }^{1}$ (1957), Piza et alii ${ }^{5}$ (1959), Ramos et alii ' (1961) e depois do trabalho experimental de Paraense \& CorrêA ${ }^{3}$ (1963). 0 mais elevado índice de parasitismo até então observado para êste planorbídeo foi de $51,3 \%$, encontrado por RAmos et alii ${ }^{6}$ (1961), no decorrer de pesquisas realizadas em Ana Dias, município de Itariri. Já naquela época se evidenciava a importância epidemiológica da tenagophila também no Vale do Ribeira. Com os resultados agora apresentados, passou a ser Pedro de Toledo a localidade onde se registraram os índices cercáricos mais elevados para êsse molusco, cuja presença já está assinalada nos municípios do Vale do Ribeira citados linhas atrás. As observações foram efetuadas no período de inverno e estação sêca, durante o qual as coleções hídricas se reduzem ou mesmo desaparecem.

Os moluscos parasitados eram pequenos, medindo alguns $5 \mathrm{~mm}$ de diâmetro, atingindo outros 11 e $12 \mathrm{~mm}$, e a maioria de 7 a $10 \mathrm{~mm}$. Após a exposição à luz, apresentavam-se muitos exemplares com infecção intensa, eliminando grande número de cercárias, e ao exame após esmagamento notava-se, além das cercárias, grande número de esporocistos.

A penetração do miracídio no molusco, bem como o desenvolvimento das formas maduras devem processar-se à temperatura abaixo de $19^{\circ} \mathrm{C}$ em natureza, pois esta temperatura foi verificada na água dos focos, em horas mais quentes do dia nesta época do ano.

Os estudos de biologia dêste molusco revestem-se da maior importância, responsável que é, pela transmissão da parasi- tose em áreas do Estado de São Paulo, onde tem se revelado altamente susceti. vel à infecção pelo Schistosoma mansoni.

Quanto ao parasita, convém lembrar a facilidade com que infecta roedores; os camundongos inoculados em laboratórios, todos se infectaram, e daqueles que foram expostos nos focos ativos $73,1 \%$ apresentaram-se parasitados pelos esquistossomos. Deve ser ressaltado que no Foco 2, onde foram observados os mais altos índices de infecção natural $(71,0 \%$ e $83,1 \%)$ a fonte de infecção para os moluscos era aparentemente pobre, de vez que aquêle curso d'água não recebe despejos de esgotos.

\section{CONCLUS O E S}

1 - Biomphalaria tenagophila é a única espécie vetora do $S$. mansoni encontrada no Vale do Ribeira.

2 - Nesta zona do Estado foram verificados os mais altos índices de infecção natural para $B$. tenagophila.

3 - Exemplares da espécie tenagoghila medindo $5 \mathrm{~mm}$ de diâmetro já se apresentam parasitados pelo trematódeo, podendo eliminar cercárias.

\section{4 - A cêpa local do Schistosoma man-} soni infecta com muita facilidade, tanto a Biomphalaria tenagophila, como os roedores.

A G R A E C I E N T O S

Os autores desejam aqui consignar os seus agradecimentos ao Sr. Mário Nogueira, da Cadeira de Parasitologia da Escola Paulista de Medicina, à Srta. Noemi Bierrenbach de Lima, do Serviço de Documentação da Secretaria da Saúde e ao Sr. Waldomiro de Deus Félix, do Laboratório Regional do Instituto Adolfo Lutz de Santos. 
RAMOS, A. da S. et al. - Focos ativos de esquistossomose mansoni no Vale do Ribeira, Estado de São Paulo, Brasil. Rev. Saúde púbi., S. Paulo, 3(1):59-65, jun. 1969.

Ramos, A. da S. et al. - Active foci of schistosomiasis mansoni in the Valley of Ribeira, State of São Paulo, Brazil. Rev. Sanide puibl., S. Paulo, 3(1):59-65, jun. 1969.

SUMmary - The results of the studies about foci of Schistosomiasis in the localities of Pedro de Toledo and Itariri, are presented with special reference to the natural infection rate, reached for the Biomphalaria tenagophila species. This snails which transmits Schistosomiasis in "Vale do Ribeira", was also found in the following counties in that region of the State of São Paulo: Eldorado, Iguape, Itariri, Jacupiranga, Juquiá, Miracatu, Pariqueraç, Pedro de Toledo, Registro and Sete Barras. The natural infection rates of $68.1 \%$; $75.0 \%$; and $81.3 \%$ obtained in some samples of $B$. tenagophila, the highest till now verified of this species, prove once more the great susceptibility to the infection by Schistosoma mansoni.

\section{REFERENCIAS BIBLIOGRAFICAS}

1. MARTINS, R. de S. - Focos ativos de esquistossomose em Niterói, Estado do Rio de Janeiro. Rev. bras. Malar., 9:361-364, jul. 1957.

2. NOGUEIRA Jr, A. R. - Relatório existente nos registros da "Campanha de Combate à Esquistossomose", 1953.

3. PARAENSE, W. L. \& CORREA, L. R. Susceptibility of Australorbis tenagophilus to infection with Schistosoma mansoni. Rev. Inst. Med. trop. S. Paulo, 5:23-29, jan./fev. 1963.

4. PIZA, J. de T. \& RAMOS, A. da S. Os focos autóctones de esquistossomose no Estado de São Paulo. Arq. Hig. Saúde públ., 25:261-271, dez. 1960.

5. PIZA, J. de T. et al. - A esquistossomose no Vale do Paraiba (Estado de São Paulo - Brasil). Observações sôbre a doença em alguns dos seus municíplos e a fauna planorbídica da regiáo. Rev. Inst. Adolfo Lutz, 19:97-143, 1959.

6. RAMOS, A. da S.; PIZA, J. de T. \& CAMARgo, L. S. V. de - Observacões sôbre Australorbis tenagophilus, transmissor da esquistossomose mansônica. Arq. Hig. Saúde públ., 26:121-124, jun. 1961. 